\title{
NOTES FOR AUTHORS
}

The Bulletin of Entomological Research publishes original research papers concerning insects, mites, ticks or other arthropods of economic importance in agriculture, forestry, stored products, biological control, medicine, animal health and natural resource management. The geographical scope of the Bulletin is worldwide but with emphasis on the tropics. Taxonomic papers are accepted if relevant. Short review papers, although normally by invitation, will also be considered for publication.

Page Format. The Bulletin is printed in a twocolumn format (column width of $80 \mathrm{~mm}$ ) with a text area of $170 \times 225 \mathrm{~mm}$.

Text. Papers should be typed, on one side of the paper only, with double line spacing and ample margins (at least $1.5 \mathrm{~cm}$ ) on each side and with no underlining or bold in text except for scientific names. Draft quality print from a word-processor is not acceptable. Standard abbreviations (e.g. fig. and figs) and metric units must be used. Guidelines for taxonomic papers are available.

When the paper has been accepted word-processed text stored on floppy disk is encouraged, providing the software is IBM/DOS compatible, but floppy discs must be accompanied by a hard copy. This will enable papers to be handled rapidly, and with fewer type-setting errors.

Abstract. Each paper must commence with a carefully prepared, accurate, informative abstract, in one paragraph, that is complete in itself and intelligible without reference to text or figures. It should not exceed 250 words. A short title should be provided as a running head.

Tables. Tables should be reduced to the simplest form, and should not be used where text or illustrations give the same information. They should be submitted on separate sheets at the end of the article and must fit conveniently into single column, full width or landscape (if absolutely necessary) format. Table captions should be typed on a separate sheet.

Illustrations. Copies only of artwork should be submitted. The original illustrations should accompany the paper after acceptance and revision. Text figures, line drawings, computer-generated figures and graphs should be of sufficient size and quality to allow for reduction by half or two-thirds. Half-tone photographs are acceptable where they are a real contribution to the text. Figure and captions should be typed on a separate sheet in the following format:

Figs 23-26. Figs 23-24, Urophora eggs: 23, U. hispanica; 24 , U. stigma. Figs 25-26, spermathecae: 25 , U. maura; 26, U. stigma; scale lines $=0.05 \mathrm{~mm}$.

Voucher specimens. The deposition of voucher specimens should be considered where appropriate.

References. References must be based on the name and year system, give full journal titles and conform to the following styles:

Powell, W. (1986) Enhancing parasitoid activity in crops. pp. 319-340 in Waage, J. \& Greathead, D. (Eds) Insect parasitoids. London, Academic Press (Symposium, Royal Entomological Suciety of London No. 13).

Southwood, T.R.E. (1978) Ecological methods with particular reference to the study of insect populations. 2nd edn. 524 pp. London, Chapman \& Hall.

Zhou, X., Carter, N. \& Mumford, J. (1989) A simulation model describing the population dynamics and damage potential of the rose grain aphid, Metopolophium dirhodum (Walker) (Hemiptera: Aphididae), in the UK. Bulletin of Entomological Research 79, 373-380.

Citation of authors in the text should appear in the form: Polaszek (1990) or (Polaszek, 1990). More than one author should be cited in chronological order as: (Holloway et al., 1987; Walker \& Huddleston, 1988).

Offprints. 50 copies of each paper are provided free to the author (or major author) of each paper. Further copies may be obtained on payment, and the number required should be specified and ordered at proof stage.

Manuscripts. Three copies of the manuscript and artwork should be submitted to:

The Editors

Bulletin of Entomological Research International Institute of Entomology 56, Queen's Gate

London

SW7 5JR, UK. 


\section{Bulletin of Entomological Research}

Guest Editorial: Miller, S. E. The information age and new technology

Bigger, M. Ant-homopteran interactions in a tropical ecosystem. Description of an experiment on cocoa in Ghana

Carlson, D. A., Milstrey, S. K. \& Narang, S. K. Classification of tsetse flies Glossina spp. (Diptera: Glossinidae) by gas chromatographic analysis of cuticular components

Chapman, P. A., Webb, D. P. \& Walker, S. J. The potential of some newer photostable pyrethroids to select for resistance in the housefly Musca domestica (Diptera: Muscidae).

Clarke, A. R. A new Trissolcus Ashmead species (Hymenoptera: Scelionidae) from Pakistan: species description and its role as a biological control agent

Coombs, M., Del Socorro, A. P., Fitt, G. P. \& Gregg, P. C. The reproductive maturity and mating status of Helicoverpa armigera, H. punctigera and Mythimna convecta (Lepidoptera: Noctuidae) collected in tower-mounted light traps in northern New South Wales, Australia

Enkegaard, A. The poinsettia strain of the cotton whitefly, Bemisia tabaci (Homoptera: Aleyrodidae), biological and demographic parameters on poinsettia (Euphorbia pulcherrima) in relation to temperature

Gerard, P. J., Perry, N. B., Ruf, L. D. \& Foster, L. M. Antifeedant and insecticidal activity of compounds from Pseudowintera colorata (Winteraceae) on the webbing clothes moth, Tineola bisselliella (Lepidoptera: Tineidae) and the Australian carpet beetle, Anthrenocerus australis (Coleoptera: Dermestidae)

Green, C. H. The effects of odours and target colour on landing responses of Glossina morsitans morsitans and G. pallidipes (Diptera: Glossinidae)

Gregg, P. C., Fitt, G. P., Coombs, M. \& Henderson, G. S. Migrating moths (Lepidoptera) collected in tower-mounted light traps in northern New South Wales, Australia: species composition and seasonal abundance.

Janssen, J. A. M. Soil nutrient availability in a primary outbreak area of the African armyworm, Spodoptera exempta (Lepidoptera: Noctuidae), in relation to drought intensity and outbreak development in Kenya....

Jayanth, K. P., Mohandas, Sukhada, Asokan, R. \& Ganga Visalakshy, P. N. Parthenium pollen induced feeding by Zygogramma bicolorata (Coleoptera: Chrysomelidae) on sunflower (Helianthus annuus) (Compositae)

Kafu, A. A., Busch-Petersen, E. \& Wood, R. J. Effects of contamination with wild-type males, virgin females or mated females, on the stability of the $\mathrm{T}: \mathrm{Y}\left(w p^{+}\right) 30 \mathrm{C}$ genetic sexing strain of Ceratitis capitata (Diptera: Tephritidae)

Matthiessen, J. N. \& Learmonth, S. E. Spatial sampling of insects, plant parts and insect attacks in the soil of potato crops

Milligan, P. J. M., Phillips, A., Broomfield, G., Molyneux, D. H., Touré, Y. \& Coluzzi, M. A Study of the use of gas chromatography of cuticular hydrocarbons for identifying members of the Anopheles gambiae (Diptera: Culicidae) complex

Rawlings, P., Ceesay, M. L., Wacher, T. J. \& Snow, W. F. The distribution of the tsetse flies Glossina morsitans submorsitans and G. palpalis gambiensis (Diptera: Glossinidae) in The Gambia and the application of survey results to tsetse and trypanosomiasis control

Starý, P. The fate of released parasitoids (Hymenoptera: Braconidae, Aphidiinae) for biological control of aphids in Chile

Symondson, W. O. C. \& Liddell, J. E. The detection of predation by Abax parallelepipedus and Pterostichus madidus (Coleoptera: Carabidae) on Mollusca using a quantitative ELISA

Williams, D. J. \& Watson, G. W. Aulacaspis (Homoptera: Diaspididae) on sugarcane and other Saccharum spp. (Gramineae)

Book Reviews

Index of Authors (Volume 83). 